Research Article

\title{
Monthly Attenuation Prediction for Asphalt Pavement Performance by Using GM $(1,1)$ Model
}

\author{
Limin Tang $\mathbb{D}^{1,2,3}$ and Duyang Xiao ${ }^{1,2,3}$ \\ ${ }^{1}$ School of Traffic and Transportation Engineering, Changsha University of Science and Technology, 960 Wanjiali S. Rd., \\ Changsha, Hunan Province 410004, China \\ ${ }^{2}$ State Engineering Laboratory of Highway Maintenance Technology, Changsha University of Science \& Technology, Changsha, \\ Hunan Province 410004, China \\ ${ }^{3}$ Co-Innovation Center for Advanced Construction and Maintenance Technology of Modem Transportation \\ Infrastructural Facility, Changsha, Hunan Province 410004, China \\ Correspondence should be addressed to Limin Tang; tlm@csust.edu.cn
}

Received 15 February 2019; Revised 21 April 2019; Accepted 7 May 2019; Published 28 May 2019

Academic Editor: Roberto Nascimbene

Copyright (C) 2019 Limin Tang and Duyang Xiao. This is an open access article distributed under the Creative Commons Attribution License, which permits unrestricted use, distribution, and reproduction in any medium, provided the original work is properly cited.

\begin{abstract}
Due to the uncertainty and variability of various factors affecting the pavement performance, the change in pavement performance cannot be completely determined. In addition, this uncertainty is not accurately reflected by the pavement performance prediction model. In particular, the gray GM $(1,1)$ model is very suitable due to it is ability to better predict the existing situation of a domestic asphalt pavement along with the actual performance of a road surface of the "small sample, poor information" gray system. In this regard, the gray GM $(1,1)$ model is being increasingly used to forecast the performance of an asphalt pavement. When a gray GM $(1,1)$ model is used to predict the performance of an asphalt pavement, the condition number of the GM $(1,1)$ model matrix is too large, which, in turn, leads to the deviation of calculation and even wrong results in some cases. This study analyzed the reason for a large condition number of the GM $(1,1)$ model matrix. Combined with the numerical characteristics of the pavement condition index (PCI) and pavement quality index (PQI), this study focused on the annual, monthly, and daily attenuations of PCI and PQI to the condition number of the GM $(1,1)$ model matrix. Accordingly, we propose a method to forecast the performance of an asphalt pavement using the monthly attenuation of PCI and PQI. The PCI and PQI in Hunan Province in recent years have been predicted, and the findings reveal that the prediction GM $(1,1)$ model for the monthly attenuation of PCI and PQI not only effectively lowered the condition number of the matrix but also ensured that the relative error was small.
\end{abstract}

\section{Introduction}

The performance of a road surface encompasses five aspects: driving quality, driving safety, structural strength, damage status, and appearance. Factors that affect pavement performance include traffic volume, structural strength, structural composition, material characteristics, and environmental factors. To that end, Fernandes conducted a study on a new asphalt mixture using waste materials and found that it can be used for road-paving works in order to improve the performance without compromising on human and environmental safety [1]. Correspondingly, Camargo and
Bernucci carried out a study in order to characterize the field performance of Brazil's first pavement rehabilitation job using a field-blended rubber asphalt mixture and attempted to predict its future performance [2]. Similarly, Kim et al. conducted a research to determine the effects of temperature segregation on the density and mechanical properties of Louisiana asphalt mixtures [3], whereas Fostinelli performed a cross-sectional study with the purpose of evaluating occupational exposure to polycyclic aromatic hydrocarbons (PAHs) in workers involved in the pavement construction of a new highway in Northern Italy, where modified bitumen was utilized as a binder for hot mix asphalt [4]. Analogously, 
Gardete adopted an approach that can be potentially very cost effective in enhancing the performance of the bituminous mixtures and achieving better/more durable pavements [5]. On the contrary, Zadshir et al. investigated the impact of three modifiers (one petroleum-based and two bio-based) on the thermomechanical properties of an oxidized asphalt binder [6]. Meanwhile, Yousefdoost et al. presented the outcomes of the project's first phase wherein a database of mechanical properties of 28 typical dense-graded Australian asphalt mixes was established, in addition to the rheological properties of their binder constituents [7]. Correspondingly, Tanakizadeh and Shafabakhsh examined existing micromechanical models such as the inverse rule of mixtures, Hashin-Shtrikman model, generalized self-consistent scheme (GSCS), and 4-phase model, with a view to determine the dynamic shear modulus of aged asphalt mastics [8]. Braswell et al. examined permeable pavement performance when built over a low-conductivity clay soil [9], while Santos et al. posited a full process-based comparative life cycle assessment (LCA) in order to obtain a better understanding of the environmental impact of reducing mixing temperature by incorporating warm mix technologies, namely, chemical additive-based and foam-based, along with different rates of recycling ( $0 \%$ and $50 \%$ RAP) [10].

The prediction of pavement performance worldwide can be broadly classified as deterministic, probabilistic, intelligent, or other types of models. Due to different conditions, many countries and regions have proposed different forms of predictive models. For example, the empirical statistical regression method, time-series analysis method, autoregressive moving average model method with difference, adaptive control Markov model method, normal Markov chain method, artificial neural network method, BP neural network method, gray methods, grayMarkov combination method, matter element method, and gray matter element method are used to predict pavement performance [11-17]. Owing to the underlying uncertainty and variability of various factors affecting the pavement performance, it is not possible to completely determine the change in pavement performance; this uncertainty, however, is not accurately reflected by the prediction model. Since Professor Deng proposed the gray system theory [18], it is being increasingly used in order to predict the performance of an asphalt pavement. Gray theory is a method to study the problem of "less data and poor information" uncertainty. It mainly realizes the correct description and effective monitoring of the system's operational behavior and evolution law by extracting valuable information from the generation and development of "partial" known information. During the past decade, major universities and scientific research institutes within the highway industry have awarded doctoral or master thesis to studies related to gray system theory in order to predict the performance of an asphalt pavement every year [19-32]. The gray GM $(1,1)$ model is particularly suitable because it can effectively predict the existing scenario of a domestic asphalt pavement and the actual performance of a road surface of the "small sample, poor information" gray system. However, the ill-conditioned predicament of the GM $(1,1)$ model matrix limits its computational accuracy. More specifically, the condition number of a gray system model matrix is larger, which poses a challenge. Many scholars do not consider the influence of ill-conditioned matrix on prediction results whilst using gray models to make predictions for asphalt pavement performance. After Professor Deng proposed the gray system theory, some scholars have attempted to analyze why the matrix was ill-conditioned or what caused the matrix to be ill-conditioned [33-38]. Against this backdrop, the main objective of this paper is to analyze the condition number of the GM $(1,1)$ model matrix which causes matrix ill-conditioning. Taking the GM $(1,1)$ model as an illustration, the rationale behind a large condition number of the $\operatorname{GM}(1,1)$ matrix was analyzed by combining the numerical characteristics of pavement performance indicators, such as the pavement condition index (PCI) and pavement quality index (PQI). Notably, the size and impact of the PCI and PQI's annual, quarterly, monthly, half-month, ten-day, and daily attenuations on the GM $(1,1)$ model matrix condition number were evaluated in this study. In addition, a method is postulated to predict the performance of an asphalt pavement based on the monthly attenuation of PCI and PQI. This method not only is more accurate than the existing prediction model of asphalt pavement performance but also effectively reduces the condition number of the gray model matrix.

\section{Research Significance}

Premised on the GM $(1,1)$ prediction model of asphalt pavement performance, this paper analyzes the size and influence of the condition number of the annual attenuation value, quarterly attenuation value, monthly attenuation value, half-month attenuation value, ten-day attenuation value, and daily attenuation value of PCI and PQI on the model matrix. Importantly, the GM $(1,1)$ model matrix condition number formed by the monthly attenuation value is the smallest after comparing the $\operatorname{GM}(1,1)$ model matrix condition numbers that are formed by the PCI and PQI's annual attenuation value, quarterly attenuation value, monthly attenuation value, half-month attenuation value, ten-day attenuation value, and daily attenuation value. To that end, a $\operatorname{GM}(1,1)$ model for predicting the performance of an asphalt pavement with the PCI and PQI's monthly attenuation value as a nonnegative smooth sequence is established, which then reduces the ill-conditioned number of the GM $(1,1)$ model matrix. Additionally, the relative error of the monthly attenuation value GM $(1,1)$ prediction models of the PCI and PQI is also smaller than that of other asphalt pavement performance prediction models.

\subsection{Reason for a Large Condition Number of $G M(1,1)$ Model Matrix}

Definition 1. Set $X^{(0)}$ as a nonnegative smooth sequence $X^{(0)}=\left(X^{(0)}(1), X^{(0)}(2), \ldots, X^{(0)}(n)\right) ; X^{(1)}$ is $X^{(0)}$ 's 1 -AGO 
sequence, $Z^{(1)}$ denotes the $X^{(1)}$ neighboring mean generation sequence, whereas $X^{(0)}(k)+a Z^{(1)}(k)=b$ is considered a gray differential equation [18]. It is also known as the definition of the GM $(1,1)$ model.

Theorem 1. Let $\widehat{a}=(a, b)^{T}$ be a $G M(1,1)$ model parameter, and

$$
\begin{aligned}
& Y=\left[\begin{array}{c}
x^{(0)}(2) \\
x^{(0)}(3) \\
\cdot \\
\cdot \\
\cdot \\
x^{(0)}(n)
\end{array}\right], \\
& B=\left[\begin{array}{cc}
-z^{(1)}(2) & 1 \\
-z^{(1)}(3) & 1 \\
\cdot & 1 \\
\cdot & 1 \\
\cdot & 1 \\
-z^{(1)}(n) & 1
\end{array}\right] .
\end{aligned}
$$

Then, the least-squares estimation parameter sequence of the gray differential equation $X^{(0)}(k)+a Z^{(1)}(k)=b$ is

$$
\widehat{a}=(a, b)^{\mathrm{T}}=\left(B^{\mathrm{T}} B\right)^{-1} B^{\mathrm{T}} Y,
$$

that is, $\left(B^{\mathrm{T}} B\right)^{-1} \widehat{a}=B^{\mathrm{T}} Y$. The coefficient matrix is as follows [16]:

$$
B^{\mathrm{T}} B=\left[\begin{array}{cc}
\sum_{k=2}^{n}\left[Z^{(1)}(k)\right]^{2} & \sum_{k=2}^{n} Z^{(1)}(k) \\
-\sum_{k=2}^{n} Z^{(1)}(k) & n-1
\end{array}\right] .
$$

Reference [34] makes the assumption that, concerning the situation of $Z^{(1)}(k)>1$, when $0<\left[\sum_{k=2}^{n} Z^{(1)}(k)\right]^{2}$ / $\sum_{k=2}^{n}\left[Z^{(1)}(k)\right]^{2} \leq n-2$, the maximum condition number value of $B^{\mathrm{T}} B$ is signified by $4 \sum_{k=2}^{n}\left[Z^{(1)}(k)\right]^{2}$. When $n-2<\left[\sum_{k=2}^{n} Z^{(1)}(k)\right]^{2} / \sum_{k=2}^{n}\left[Z^{(1)}(k)\right]^{2} \leq n-1$, the condition number of $B^{\mathrm{T}} B$ is predicated on the extent to which $\left[\sum_{k=2}^{n} Z^{(1)}(k)\right]^{2} / \sum_{k=2}^{n}\left[Z^{(1)}(k)\right]^{2}$ is close to $n-1$.

When $\left[\sum_{k=2}^{n} Z^{(1)}(k)\right]^{2} / \sum_{k=2}^{n}\left[Z^{(1)}(k)\right]^{2} \longrightarrow n-1$, the matrix witnesses a severe drift. Notably, the gray system studies small samples; however, in actual production and life, the value of $Z^{(1)}(k)$ varies significantly with actual production and life issues. If $Z^{(1)}(k)>10$ or above, the value of $4 \sum_{k=2}^{n}\left[Z^{(1)}(k)\right]^{2}$ is also larger. In other words, the condition number of the matrix $B^{\mathrm{T}} B$ is correspondingly larger, which, in turn, leads to the morbid matrix. When $n-2<$ $\left[\sum_{k=2}^{n} Z^{(1)}(k)\right]^{2} / \sum_{k=2}^{n}\left[Z^{(1)}(k)\right]^{2} \leq n-1$, the condition number of $B^{\mathrm{T}} B$ is predicated on the extent to which $\left[\sum_{k=2}^{n} Z^{(1)}(k)\right]^{2} / \sum_{k=2}^{n}\left[Z^{(1)}(k)\right]^{2}$ is close to $n-1$. According to example 6.1 in reference [18],

$$
4-2=2<\frac{\left[\sum_{k=2}^{n} Z^{(1)}(k)\right]^{2}}{\sum_{k=2}^{n}\left[Z^{(1)}(k)\right]^{2}}=2.708954 \leq 4-1=3 .
$$

Currently, the condition number of the GM $(1,1)$ model matrix is 249098.48. The criteria of an ill-conditioned matrix's conditional number size are as follows: good condition $(<10)$, mild ill condition $(10,100)$, strong ill condition $(100,1000)$, and severe ill condition (>1000) [38]; meanwhile, $B^{\mathrm{T}} B$ is severely ill. Different ill-conditioned degrees of the matrix will result in an unstable or even wrong solution of the model.

2.2. Number of GM $(1,1)$ Matrix Conditions with Different Attenuations of PCI and PQI. Section 2.1 points out that if $Z^{(1)}(k)>10$ or above, when $0<\left[\sum_{k=2}^{n} Z^{(1)}(k)\right]^{2} /$ $\sum_{k=2}^{n}\left[Z^{(1)}(k)\right]^{2} \leq n-2$, then the value of $4 \sum_{k=2}^{n}\left[Z^{(1)}(k)\right]^{2}$ is also larger. In terms of the performance indicators of an asphalt pavement, the road surface condition index (PCI) and the driving quality index (PQI) are usually 100 points. Table 1 depicts the pavement performance indexes of three representative lines of main highways in Hunan over the past few years [31].

In the event that the detected values of PCI and PQI are directly used as the $X^{(0)}$ nonnegative smoothing sequences within the GM $(1,1)$ model, the resulting number of matrix $B^{\mathrm{T}} B$ conditions is very large. Table 2 illustrates the condition number of the GM $(1,1)$ model matrix obtained by directly using the values of PCI and PQI.

Considering the PCI of line 1 as the $X^{(0)}$ sequence, the GM $(1,1)$ model matrix $B^{\mathrm{T}} B$ is $\left[\begin{array}{cc}593990 & -1618 \\ -1618 & 5\end{array}\right]$, whereas the condition number is 1002500 . According to Table 2, the condition number of the matrix obtained by directly using the values of PCI and PQI is far beyond the range of severe ill condition $(>1000)$.

2.2.1. Condition Number of Matrix Based on the Annual Attenuations of PCI and PQI. Asphalt pavement performance indicators are inclusive of PCI and PQI. In the initial period without any maintenance, their values reduce each year from the beginning of operation; in other words, the road surface condition and driving quality deteriorate by the year. Meanwhile, the annual attenuations of PCI and PQI can be defined as the PCI and PQI values for the previous year minus those pertaining to the current year. Taking the example of the period from 2013 to 2014, these attenuations can be obtained by subtracting the PCI and PQI values for 2014 from the PCI and PQI values for 2013. Owing to the year-by-year decay nature of PCI and PQI values, this approach ensures the annual attenuation satisfies the requirement that $X^{(0)}$ is a nonnegative smooth sequence in the GM $(1,1)$ model. Meanwhile, Table 3 depicts the PCI and PQI's annual attenuations of three representative lines of the main highways in Hunan Province listed in Table 2.

After obtaining the annual attenuations of PCI and PQI, the annual attenuation was used as the nonnegative smooth 
TABLE 1: PCI and PQI of three typical representative lines of the main highway in Hunan Province.

\begin{tabular}{|c|c|c|c|c|c|c|}
\hline \multirow{2}{*}{ Year of detection } & \multicolumn{3}{|c|}{ PCI } & \multicolumn{3}{|c|}{ PQI } \\
\hline & Line 1 & Line 2 & Line 3 & Line 1 & Line 2 & Line 3 \\
\hline Early 2012 & - & - & 100 & - & - & 97.59 \\
\hline Early 2013 & 100 & 100 & 98.24 & 97.4 & 96.96 & 96.07 \\
\hline Early 2014 & 98.14 & 97.59 & 93.35 & 95.33 & 95.32 & 92.44 \\
\hline Early 2015 & 90.57 & 90.89 & 88.54 & 89.85 & 90.88 & 89.48 \\
\hline Early 2016 & 83.43 & 86.79 & 81.89 & 84.72 & 86.44 & 83.85 \\
\hline Early 2017 & 76.93 & 81.41 & 77.86 & 79.84 & 82.40 & 81.01 \\
\hline Early 2018 & 70.86 & 77.31 & 72.90 & 75.25 & 78.41 & 77.16 \\
\hline
\end{tabular}

TABle 2: Condition number of the GM $(1,1)$ model matrix obtained by directly using the values of PCI and PQI.

\begin{tabular}{|c|c|c|c|c|c|c|}
\hline & \multicolumn{3}{|c|}{ PCI } & \multicolumn{3}{|c|}{ PQI } \\
\hline & Line 1 & Line 2 & Line 3 & Line 1 & Line 2 & Line 3 \\
\hline Condition number of the matrix & 1002500 & 990325 & 1191000 & 945050 & 939600 & 1137200 \\
\hline
\end{tabular}

TABLe 3: Annual attenuations of PCI and PQI for three representative lines of the main highway in Hunan Province.

\begin{tabular}{lcccccc}
\hline & \multicolumn{3}{c}{ Annual attenuation of } & \multicolumn{3}{c}{ Annual attenuation of } \\
& \multicolumn{3}{c}{ PCI } & & \multicolumn{3}{c}{ PQI } \\
& Line 1 & Line 2 & Line 3 & Line 1 & Line 2 & Line 3 \\
\hline 2012/year & - & - & 1.76 & - & - & 1.52 \\
2013/year & 1.86 & 2.41 & 4.89 & 2.07 & 1.64 & 3.63 \\
2014/year & 7.57 & 6.7 & 4.81 & 5.48 & 4.44 & 2.96 \\
2015/year & 7.14 & 4.1 & 6.65 & 5.13 & 4.44 & 5.63 \\
2016/year & 6.50 & 5.38 & 4.03 & 4.88 & 4.04 & 2.84 \\
2017/year & 6.07 & 4.1 & 4.96 & 4.59 & 3.99 & 3.85 \\
\hline
\end{tabular}

sequence of $X^{(0)}$ in the GM $(1,1)$ model. The model parameter $\widehat{a}=(a, b)^{\mathrm{T}}$ was solved using equations (1) and (2). Table 4 illustrates the condition number of the $\operatorname{GM}(1,1)$ model matrix $B^{\mathrm{T}} B$ that was obtained using the PCI and PQI's annual attenuations.

The PCI's annual attenuation of line 3 denotes the $X^{(0)}$ sequence. The GM $(1,1)$ model matrix $B^{\mathrm{T}} B$ is $\left[\begin{array}{cc}1329.4 & -72.79 \\ -72.79 & 5\end{array}\right]$, whereas the condition number is 1318.2. Importantly, the condition number of the GM $(1,1)$ model matrix derived using the annual attenuation is partially in a severely ill-conditioned state $(>1000)$ and partly in a relatively strong ill-conditioned state $(100,1000)$.

2.2.2. Condition Number of Matrix Based on the Monthly Attenuations of PCI and PQI. The monthly attenuations of both PCI and PQI can be defined as the annual attenuations of PCI and PQI evenly distributed to 12 months per year; that is, monthly attenuation of PCI and PQI = annual attenuation of PCI and PQI/12. Table 5 illustrates the monthly attenuations of PCI and PQI for three typical representative line pavements in Hunan Province.

After obtaining the monthly attenuations of PCI and PQI, the monthly attenuation was considered the $X^{(0)}$ nonnegative smooth sequence within the GM $(1,1)$ model. The model parameter $\widehat{a}=(a, b)^{\mathrm{T}}$ was solved using equations
(1) and (2). Table 6 illustrates the condition number of the GM $(1,1)$ model matrix $B^{\mathrm{T}} B$ that was obtained using the monthly attenuations of PCI and PQI.

The monthly attenuation of PQI of line 2 represents the $X^{(0)}$ sequence. The $\mathrm{GM}(1,1)$ model matrix $B^{\mathrm{T}} B$ is $\left[\begin{array}{cc}3.5771 & -3.4379 \\ -3.4379 & 4\end{array}\right]$, whereas the condition number is 21.02. It may be important to note that the condition number of the matrix obtained using the monthly attenuation lies in the slightly ill-conditioned range $(10,100)$.

2.2.3. Condition Number of Matrix Based on the Daily Attenuations of PCI and PQI. The daily attenuations of PCI and PQI can be defined as the annual attenuations of PCI and PQI evenly distributed to 365 days per year; that is, monthly attenuation of PCI and PQI = annual attenuation of PCI and PQI/365. Table 7 depicts the daily attenuations of both PCI and PQI for three typical representative line pavements in Hunan Province.

After obtaining the daily attenuations of PCI and PQI, the daily attenuation was utilized as the $X^{(0)}$ nonnegative smooth sequence within the GM $(1,1)$ model, whereas the model parameter $\widehat{a}=(a, b)^{\mathrm{T}}$ was solved using equations (1) and (2). Table 8 illustrates the condition number of the GM $(1,1)$ model matrix $B^{\mathrm{T}} B$ that was obtained using the daily attenuations of PCI and PQI.

The monthly attenuation of PQI of line 3 signifies the $X^{(0)}$ sequence. The $\mathrm{GM}(1,1)$ model matrix $B^{\mathrm{T}} B$ is $\left[\begin{array}{cc}0.0056 & -0.1495 \\ -0.1495 & 5\end{array}\right]$, whereas the condition number is 4406.3. The condition numbers of the matrix obtained using the daily attenuations are in the severely ill-conditioned range $(>1000)$.

A comparison between the data shown in Tables 3-8 revealed that when taking the annual attenuation of PCI or PQI, the condition number of the $\operatorname{GM}(1,1)$ model matrix is in the strong and severely ill-conditioned range. Meanwhile, when considering the daily attenuation, the matrix 
TABle 4: Condition number of the GM $(1,1)$ model matrix using annual attenuations of PCI and PQI.

\begin{tabular}{|c|c|c|c|c|c|c|}
\hline & \multicolumn{3}{|c|}{ Annual attenuation of PCI } & \multicolumn{3}{|c|}{ Annual attenuation of PQI } \\
\hline & Line 1 & Line 2 & Line 3 & Line 1 & Line 2 & Line 3 \\
\hline Condition number of the matrix & 1754.8 & 1445.2 & 1318.2 & 1122.8 & 749.75 & 744.20 \\
\hline
\end{tabular}

TABle 5: Monthly attenuations of PCI and PQI for three typical representative lines of highways in Hunan Province.

\begin{tabular}{|c|c|c|c|c|c|c|}
\hline & \multicolumn{3}{|c|}{ Monthly attenuation of PCI } & \multicolumn{3}{|c|}{ Monthly attenuation of PQI } \\
\hline & Line 1 & Line 2 & Line 3 & Line 1 & Line 2 & Line 3 \\
\hline 2012/month & - & - & 0.1467 & - & - & 0.1267 \\
\hline 2013/month & 0.1550 & 0.2008 & 0.4075 & 0.1725 & 0.1367 & 0.3025 \\
\hline 2014/month & 0.6308 & 0.5583 & 0.4008 & 0.4567 & 0.3700 & 0.2467 \\
\hline 2015/month & 0.5950 & 0.3417 & 0.5542 & 0.4275 & 0.3700 & 0.4692 \\
\hline 2016/month & 0.5417 & 0.4483 & 0.3358 & 0.4067 & 0.3367 & 0.2367 \\
\hline 2017/month & 0.5058 & 0.3417 & 0.4133 & 0.3825 & 0.3325 & 0.3208 \\
\hline
\end{tabular}

TABle 6: Condition number of the GM $(1,1)$ model matrix using the monthly attenuations of PCI and PQI.

\begin{tabular}{|c|c|c|c|c|c|c|}
\hline & \multicolumn{3}{|c|}{ Monthly attenuation of PCI } & \multicolumn{3}{|c|}{ Monthly attenuation of PQI } \\
\hline & Line 1 & Line 2 & Line 3 & Line 1 & Line 2 & Line 3 \\
\hline Condition number of the matrix & 23.51 & 26.34 & 19.57 & 22.16 & 21.02 & 17.67 \\
\hline
\end{tabular}

Table 7: Daily attenuations of PCI and PQI for three typical representative lines of main trunk highways in Hunan Province.

\begin{tabular}{lcccrr}
\hline & & Daily attenuation of PCI & \multicolumn{2}{c}{ Daily attenuation of PQI } \\
& Line 1 & Line 2 & Line 3 & Line 1 & - \\
2012/daily & - & - & 0.0048 & - & 0.0042 \\
2013/daily & 0.0051 & 0.0066 & 0.0134 & 0.0057 & 0.0045 \\
2014/daily & 0.0207 & 0.0184 & 0.0132 & 0.0150 & 0.0122 \\
2015/daily & 0.0196 & 0.0112 & 0.0182 & 0.0141 & 0.0122 \\
2016/daily & 0.0178 & 0.0147 & 0.0110 & 0.0134 & 0.0111 \\
2017/daily & 0.0166 & 0.0112 & 0.0136 & 0.0126 & 0.0154 \\
\hline
\end{tabular}

TABle 8: Condition number of the GM $(1,1)$ model matrix using the daily attenuations of PCI and PQI.

\begin{tabular}{lcccccc}
\hline & \multicolumn{3}{c}{ Daily attenuation of PCI } & \multicolumn{3}{c}{ Daily attenuation of PQI } \\
& Line 1 & Line 2 & Line 3 & Line 1 & Line 2 & Line 3 \\
\hline Condition number of the matrix & 2297.6 & 4378.0 & 2477.2 & 4246.6 & 5956.0 & 4406.3 \\
\hline
\end{tabular}

condition number lies in the severely ill-conditioned range. Finally, the matrix condition number is in the slightly illconditioned range when taking the monthly attenuation.

According to the authors' calculations, if the quarterly, half-month, and ten-day attenuations of PCI or PQI are used, the resulting condition number of the matrix is higher than that of the monthly attenuation.

For this reason, the monthly attenuation of PCI or PQI was used in this paper as the initial $X^{(0)}$ nonnegative smoothing sequence in the GM $(1,1)$ model in order to forecast the performance of an asphalt pavement.

\section{Prediction Model of Asphalt Pavement Performance Using Reduced Condition Number of Matrix}

Considering the matrix $B^{\mathrm{T}} B$ calculated in Section 2 using different values of PCI or PQI, it can be easily observed that, since the GM $(1,1)$ model matrix $B^{\mathrm{T}} B$ is a symmetric matrix, the value corresponding to the second row and second column of the matrix is $n-1$. The calculation theory of condition numbers demonstrates that it is only when the other three numbers of the matrix $B^{\mathrm{T}} B$ and $n-1$ 
are an order of magnitude that the condition number will be reduced below the level of mild ill condition. To illustrate this, in the matrix $\left[\begin{array}{cc}1329.4 & -72.79 \\ -72.79 & 5\end{array}\right]$ that was obtained from the annual attenuation, $n-1$ has a value of 5 , which is only a single digit, whereas the others are at least a hundred, sometimes even reaching a thousand 1329.4. In the matrix $\left[\begin{array}{cc}3.5771 & -3.4379 \\ -3.4379 & 4\end{array}\right]$ obtained from the monthly attenuation, $n-1$ has a value of 4 , which again is a single digit. Additionally, the other three values are all single digits as well; therefore, the condition number is not large. During the usage of the daily attenuation, the magnitude of difference between the other three numbers and $n-1$ became larger, thereby increasing the condition number accordingly.

Using the monthly attenuation of PCI or PQI, the GM (1, 1) model used for predicting the performance of an asphalt pavement is as follows:

Let $X^{(0)}$ be the annual value of a nonnegative smoothing sequence of order $X_{1 / 12}^{(0)}=\left(\left(X^{(0)}(1)-X^{(0)}(2)\right) / 12,\left(X^{(0)}\right.\right.$ $\left.\left.(2)-X^{(0)}(3)\right) / 12, \ldots,\left(X^{(0)}(n-1)-X^{(0)}(n)\right) / 12\right) . X_{1 / 12}^{(1)}$ denotes the 1-AGO sequence of $X_{1 / 12}^{(0)} ; Z_{1 / 12}^{(1)}$ refers to the close neighboring mean generating sequence of $X_{1 / 12}^{(1)}$; and $\left(X^{(0)}(k-1)-X^{(0)}(k)\right) / 12+a Z_{1 / 12}^{(1)}(k)=b$ signifies the gray differential equation. Let $\widehat{a}=(a, b)^{\mathrm{T}}$ be the $\operatorname{GM}(1,1)$ model parameter, and

$$
\begin{aligned}
& Y=\left[\begin{array}{c}
\frac{\left(x^{(0)}(2)-x^{(0)}(3)\right)}{12} \\
\frac{\left(x^{(0)}(3)-x^{(0)}(4)\right)}{12} \\
\vdots \\
\frac{\left(x^{(0)}(n-1)-x^{(0)}(n)\right)}{12}
\end{array}\right], \\
& B=\left[\begin{array}{cc}
-Z_{1 / 12}^{(1)}(2) & 1 \\
-Z_{1 / 12}^{(1)}(3) & 1 \\
\vdots & \vdots \\
-Z_{1 / 12}^{(1)}(n) & 1
\end{array}\right] .
\end{aligned}
$$

The least-squares estimation parameter sequence of the gray differential equation $\left(X^{(0)}(k-1)-X^{(0)}(k)\right) / 12+$ $a Z_{1 / 12}^{(1)}(k)=b$ is

$$
\widehat{a}=(a, b)^{\mathrm{T}}=\left(B^{\mathrm{T}} B\right)^{-1} B^{\mathrm{T}} Y .
$$

Both equations (5) and (6) are GM $(1,1)$ prediction models for asphalt pavement performance; they are capable of reducing the condition number of the matrix. Each value in the sequence denotes the monthly attenuation of PCI or PQI.

\section{Prediction of Asphalt Pavement Performance of the Main Highway in Hunan Province}

In the trunk highways of Hunan Province, the evaluation of the performance of asphalt pavements was carried out in accordance with the standard "Highway Performance Assessment Standards" (JTG H20-2007) (China). For the roads of Grade II and below Grade II, the road pavement technical condition evaluation index adopts the pavement quality index (PQI), which consists of two individual indicators, namely, the pavement condition index (PCI) and the pavement driving quality index (RQI).

For the trunk highways, the pavement damage and the flatness technical condition are detected by automatic detection equipment, that is, the multifunctional rapid comprehensive detection vehicle. The equipment can not only identify various types of pavement diseases specified in the "Highway Performance Assessment Standards" (JTG H202007) but also meet the requirements of the specifications. After the detection vehicle is detected, the pavement damage image is recognized by the artificial assistant software, and the PCI is obtained. The pavement flatness data are analyzed and processed by special software to obtain the driving quality index (RQI) The detection vehicle and software to obtain PCI and RQI are shown in Figure 1.

The pavement quality index (PQI) is calculated according to the following equation:

$$
\mathrm{PQI}=0.6 \times \mathrm{PCI}+0.4 \times \mathrm{RQI},
$$

where PCI is the pavement condition index and RQI is the pavement driving quality index.

The pavement condition index (PCI) is calculated according to the following equations:

$$
\begin{aligned}
& \mathrm{PCI}=100-15 \mathrm{DR}^{0.412}, \\
& \mathrm{DR}=100 \times \sum_{i=1}^{21} \frac{\left(w_{i} A_{i}\right)}{A},
\end{aligned}
$$

where DR is the pavement breakage rate (\%), the sum of the various damaged areas and the percentage of the surveyed pavement area; $A_{i}$ is the $i$-type area of a pavement damage; $A$ is the survey of the pavement area; $w_{i}$ is the weight of the $i$ type damage to the pavement; and $i$ is the type of pavement damage in the item considering the degree of damage.

The pavement smoothness is calculated by the pavement driving quality index (RQI), according to the following equation, and the test data are stored for a long time in units of $100 \mathrm{~m}$ :

$$
\mathrm{RQI}=\frac{100}{\left(1+a_{0} e^{a_{1} \mathrm{IRI}}\right)},
$$

where IRI is International Flatness Index, $a_{0}$ is 0.026 for primary roads and 0.0185 for other grades of highways, and $a_{1}$ is 0.65 for the first-class roads and 0.58 for other grades of roads.

The provincial highway of Hunan Province has witnessed rapid-paced development over the past decade. With the 


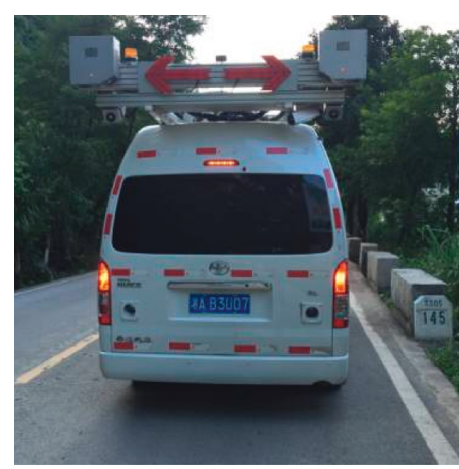

(a)

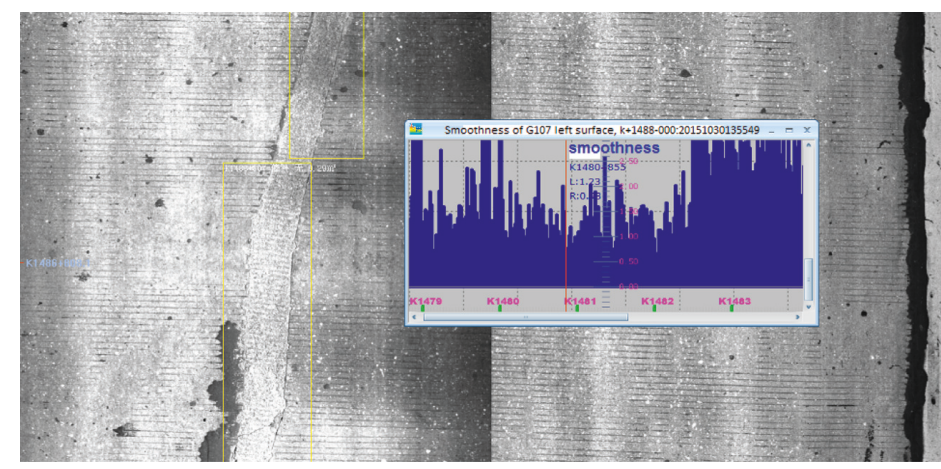

(b)

FIgURE 1: ZOYON-RTM intelligent road detection vehicle (a) and road image processing software (b).

drastic increase in traffic pressure, the pavement condition index of main highways has decreased year by year. The main highways have entered extensive maintenance and overhaul periods in recent years. The determination of maintaining the asphalt pavement and timing of major repairs, as well as the allocation of maintenance funds, necessitates a clearer understanding about the future changes in pavement conditions.

The representative lines of the main trunk highway are secondary (technical level) and heavy traffic (traffic level), and the overhaul plan is divided into "white to black" and "black to black." The construction of each layer is carried out after the previous structural layer meets the requirements, but the influence of different original pavements on the performance of the asphalt pavement will be different. Therefore, when the representative lines of the main trunk highway are selected, they are classified according to the overhaul plan. Different structural materials are one of the main factors affecting the performance of an asphalt pavement and should also be classified when selecting representative lines of the main trunk highway. Due to numerous trunk highways in Hunan Province and the complicated maintenance history, the most general situation was selected for comprehensive statistics.

The PCI and PQI of three typical representative routes were predicted in this study based on the monthly attenuations of PCI or PQI. Tables 9 and 10 illustrate pavements of the Hunan main highway based on the monthly attenuations of PCI and PQI.

To illustrate this, the predicted monthly attenuation of PCI of line 1 was calculated as $\mathrm{X}(k+1)=-8.7404 \times$ $\exp (-0.075274 \times k)+8.8954$. The predicted value is $\mathrm{X}(k+1)-\mathrm{X}(\mathrm{k})$. Suppose $\mathrm{X}(6)=-8.7404 \times \exp (-0.07527 \times k)$ $+8.8954=2.8964$ and $\mathrm{X}(5)=-8.7404 \times \exp (-0.075274 \times k)$ $+8.8954=2.4274$. Then, $\mathrm{X}(6)-\mathrm{X}(5)=0.4690$. It denotes the predicted monthly attenuation of PCI of line 1 in 2018. Similarly, according to the aforementioned method, the predicted monthly attenuations of PCI of lines 2 and 3 were calculated after the prediction calculation. Among them, the predicted monthly attenuation of PCI of line 2 was calculated as $\mathrm{X}(k+1)=-4.0328 \times \exp (-0.13542 \times k)+4.2336$. Likewise, the predicted monthly attenuation of PCI of line 3 was calculated as $\mathrm{X}(k+1)=-36.1908 \times \exp (-0.012024 \times k)+$ 36.3374 .
The predicted monthly attenuation of PQI of line 1 was calculated as $\mathrm{X}(k+1)=-8.0464 \times \exp (-0.058269 \times k)+$ 8.2189. Similarly, the predicted monthly attenuation of $\mathrm{PQI}$ of line 2 was calculated as $\mathrm{X}(k+1)=-9.2576 \times \exp$ $(-0.041277 \times k)+9.3943$. Likewise, the predicted monthly attenuation of PQI of line 3 was calculated as $\mathrm{X}(k+1)=$ $38.6564 \times \exp (0.0079912 \times k)-38.5298$.

The predicted monthly attenuation value of PCI or PQI was then multiplied by 12 and converted into the annual attenuation. Subsequently, as illustrated in Tables 11 and 12, the predicted PCI or PQI of the current year was obtained by subtracting the measured PCI or PQI values of the previous year.

Table 13 depicts that the predicted relative error of line 2 in this study is comparable with that of the standard decay equation [11] postulated by the Sun Lijun team of Tongji University as well as the method proposed in the document [31]. The findings demonstrate that the prediction capability in this paper is better than that of the other two methods. As compared to the prediction errors of lines 1 and 3 , the model proposed in this paper is also much better than Sun Lijun model as well as the model postulated in the literature [31]. However, only the comparative results of line 2 are shown in Table 13 due to space constraints.

During the last part of early 2018, the relative error of PCI prediction of line 2 was shown to be 0.33 in the Sun Lijun model, 0.92 in reference [31], and 0 in this paper. For the same period, the relative error of PQI prediction of line 2 was 0.16 in the Sun Lijun model, 0.63 in reference [31], and -0.028 in this paper. Notably, if the absolute value of relative error is compared with the PCI and PQI of all the other years, this model forecasts the absolute value of relative error, most of which are much smaller than those of the models proposed by Sun Lijun and reference [31].

\section{Conclusion}

The predicament of predicting the performance of an asphalt pavement is confronted during the precise design and maintenance of durable asphalt pavements. The foundation for solving this problem is determining the type of model to be used for prediction in addition to the capability of the model. This paper focuses on the GM $(1,1)$ model which is 
TABLE 9: Monthly attenuation prediction of three typical expressway pavements of the Hunan main highway.

\begin{tabular}{|c|c|c|c|c|c|c|}
\hline & \multicolumn{6}{|c|}{ Monthly attenuation of measured and predicted PCI } \\
\hline & $\begin{array}{c}\text { Line } 1 \\
\text { measured value }\end{array}$ & $\begin{array}{c}\text { Line } 1 \\
\text { predicted value }\end{array}$ & $\begin{array}{c}\text { Line } 2 \\
\text { measured value }\end{array}$ & Line 2 predicted value & Line 3 measured value & Line 3 predicted value \\
\hline $\begin{array}{l}\text { 2012/ } \\
\text { month }\end{array}$ & - & & - & & 0.1467 & 0.1467 \\
\hline $\begin{array}{l}\text { 2013/ } \\
\text { month }\end{array}$ & 0.1550 & 0.1150 & 0.2008 & 0.2008 & 0.4075 & 0.4326 \\
\hline $\begin{array}{l}\text { 2014/ } \\
\text { month }\end{array}$ & 0.6308 & 0.6338 & 0.5583 & 0.5108 & 0.4008 & 0.4274 \\
\hline $\begin{array}{l}\text { 2015/ } \\
\text { month }\end{array}$ & 0.5950 & 0.5878 & 0.3417 & 0.4461 & 0.5542 & 0.4223 \\
\hline $\begin{array}{l}2016 / \\
\text { month }\end{array}$ & 0.5042 & 0.5452 & 0.4483 & 0.3896 & 0.3358 & 0.4172 \\
\hline $\begin{array}{l}\text { 2017/ } \\
\text { month }\end{array}$ & 0.5058 & 0.5057 & 0.3417 & 0.3402 & 0.4133 & 0.4122 \\
\hline $\begin{array}{l}\text { 2018/ } \\
\text { month }\end{array}$ & & 0.4690 & & 0.2971 & & 0.4073 \\
\hline $\begin{array}{l}\text { 2019/ } \\
\text { month }\end{array}$ & & 0.4350 & & 0.2595 & & 0.4024 \\
\hline
\end{tabular}

Table 10: Predicted monthly attenuations of PQI for three representative lines of the main trunk highway in Hunan Province.

\begin{tabular}{|c|c|c|c|c|c|c|}
\hline & \multicolumn{6}{|c|}{ Monthly attenuation of measured and predicted PQI } \\
\hline & $\begin{array}{c}\text { Line } 1 \text { measured } \\
\text { value }\end{array}$ & $\begin{array}{l}\text { Line } 1 \text { predicted } \\
\text { value }\end{array}$ & $\begin{array}{c}\text { Line } 2 \text { measured } \\
\text { value }\end{array}$ & Line 2 predicted value & Line 3 measured value & Line 3 predicted value \\
\hline $\begin{array}{l}\text { 2012/ } \\
\text { month }\end{array}$ & - & & - & & 0.1267 & 0.1267 \\
\hline $\begin{array}{l}2013 / \\
\text { month }\end{array}$ & 0.1725 & 0.1725 & 0.1367 & 0.1367 & 0.3025 & 0.3102 \\
\hline $\begin{array}{l}\text { 2014/ } \\
\text { month }\end{array}$ & 0.4567 & 0.4555 & 0.3700 & 0.3743 & 0.2467 & 0.3126 \\
\hline $\begin{array}{l}2015 / \\
\text { month }\end{array}$ & 0.4275 & 0.4297 & 0.3700 & 0.3592 & 0.4692 & 0.3151 \\
\hline $\begin{array}{l}2016 / \\
\text { month }\end{array}$ & 0.4067 & 0.4050 & 0.3367 & 0.3447 & 0.2367 & 0.3177 \\
\hline $\begin{array}{l}\text { 2017/ } \\
\text { month }\end{array}$ & 0.3825 & 0.3824 & 0.3325 & 0.3307 & 0.3208 & 0.3202 \\
\hline $\begin{array}{l}\text { 2018/ } \\
\text { month }\end{array}$ & & 0.3608 & & 0.3174 & & 0.3228 \\
\hline $\begin{array}{l}\text { 2019/ } \\
\text { month }\end{array}$ & & 0.3403 & & 0.3045 & & 0.3254 \\
\hline
\end{tabular}

extensively used in asphalt pavement performance prediction and draws the following conclusions:

(1) The direct phenomenon that renders the matrix conditional number excessively large in the gray GM $(1,1)$ model is too large for the difference between the other three numbers in the matrix and $n-1$.

(2) Using the original values of PCI and PQI as the $X^{(0)}$ nonnegative smoothing sequence in the $\operatorname{GM}(1,1)$ model, the generated matrix entails a large number of conditions and forms an ill-conditioned matrix.

(3) After comparing the condition number of the GM (1, 1) matrix formed by the annual, quarterly, monthly, half-month, ten-day, and daily attenuations of PCI and PQI, the condition number of the GM $(1,1)$ matrix formed by the monthly attenuation was found to be the minimum.
(4) The GM $(1,1)$ model for forecasting the performance of an asphalt pavement using PCI and PQI is premised on the monthly attenuation as the $X^{(0)}$ nonnegative smoothing sequence.

(5) The relative error of the monthly attenuation of the GM $(1,1)$ prediction model is also smaller than that of the other models that have been proposed by references.

Since PCI and PQI adopt the 100-point system in China, when using the annual PCI and PQI, the condition number of the matrix is large in the $\operatorname{GM}(1,1)$ model prediction. When using monthly attenuations of PCI and PQI, the condition number of the GM $(1,1)$ model matrix is small. So this method is applicable to the analysis of PCI and PQI raw data of the pavement for the Chinese Hunan Province conditions. 
TABLe 11: Measured and predicted PCI for three typical roads of the trunk highway in Hunan Province.

\begin{tabular}{|c|c|c|c|c|c|c|c|c|c|}
\hline & \multicolumn{9}{|c|}{ Measured and predicted PCI } \\
\hline & $\begin{array}{c}\text { Line } 1 \\
\text { measured } \\
\text { value }\end{array}$ & $\begin{array}{c}\text { Line } 1 \\
\text { predicted } \\
\text { value }\end{array}$ & $\begin{array}{c}\text { Relative } \\
\text { error } \\
(\%)\end{array}$ & $\begin{array}{c}\text { Line } 2 \\
\text { measured value }\end{array}$ & $\begin{array}{c}\text { Line } 2 \\
\text { predicted value }\end{array}$ & $\begin{array}{c}\text { Relative } \\
\text { error } \\
(\%)\end{array}$ & $\begin{array}{c}\text { Line } 3 \\
\text { measured value }\end{array}$ & $\begin{array}{c}\text { Line } 3 \\
\text { predicted value }\end{array}$ & $\begin{array}{l}\text { Relative } \\
\text { error (\%) }\end{array}$ \\
\hline $\begin{array}{l}\text { Early } \\
2012\end{array}$ & - & & & - & & & 100 & 100 & \\
\hline $\begin{array}{l}\text { Early } \\
2013\end{array}$ & 100 & 100 & & 100 & 100 & & 98.24 & 98.24 & 0 \\
\hline $\begin{array}{l}\text { Early } \\
2014\end{array}$ & 98.14 & 98.62 & -0.489 & 97.59 & 97.59 & 0 & 93.35 & 93.05 & 0.323 \\
\hline $\begin{array}{l}\text { Early } \\
2015\end{array}$ & 90.57 & 90.53 & 0.039 & 90.89 & 91.46 & -0.627 & 88.54 & 88.22 & 0.360 \\
\hline $\begin{array}{l}\text { Early } \\
2016\end{array}$ & 83.43 & 83.52 & -0.104 & 86.79 & 85.54 & 1.444 & 81.89 & 83.47 & -1.932 \\
\hline $\begin{array}{l}\text { Early } \\
2017\end{array}$ & 76.93 & 76.89 & 0.055 & 81.41 & 82.11 & -0.866 & 77.86 & 76.88 & 1.254 \\
\hline $\begin{array}{l}\text { Early } \\
2018\end{array}$ & 70.86 & 70.86 & 0 & 77.31 & 77.33 & -0.023 & 72.90 & 72.91 & -0.019 \\
\hline $\begin{array}{l}\text { Early } \\
2019\end{array}$ & & 65.23 & & & 73.74 & & & 68.01 & \\
\hline
\end{tabular}

TABLE 12: Measured and predicted PQI for three typical roads of the trunk highway in Hunan Province.

\begin{tabular}{|c|c|c|c|c|c|c|c|c|c|}
\hline & & & & Mea & ured and predicte & PQI & & & \\
\hline & $\begin{array}{c}\text { Line } 1 \\
\text { measured } \\
\text { value }\end{array}$ & $\begin{array}{c}\text { Line } 1 \\
\text { predicted } \\
\text { value }\end{array}$ & $\begin{array}{l}\text { Relative } \\
\text { error (\%) }\end{array}$ & $\begin{array}{c}\text { Line } 2 \\
\text { measured } \\
\text { value }\end{array}$ & $\begin{array}{l}\text { Line } 2 \text { predicted } \\
\text { value }\end{array}$ & $\begin{array}{l}\text { Relative } \\
\text { error (\%) }\end{array}$ & $\begin{array}{c}\text { Line } 3 \text { measured } \\
\text { value }\end{array}$ & $\begin{array}{c}\text { Line } 3 \\
\text { predicted } \\
\text { value }\end{array}$ & $\begin{array}{c}\text { Relative } \\
\text { error } \\
(\%)\end{array}$ \\
\hline $\begin{array}{l}\text { Early } \\
2012\end{array}$ & - & & & - & & & 97.59 & 97.59 & \\
\hline $\begin{array}{l}\text { Early } \\
2013\end{array}$ & 97.4 & 97.4 & & 96.96 & 96.96 & & 96.07 & 96.07 & 0 \\
\hline $\begin{array}{l}\text { Early } \\
2014\end{array}$ & 95.33 & 95.33 & 0 & 95.32 & 95.32 & 0 & 92.44 & 92.35 & 0.100 \\
\hline $\begin{array}{l}\text { Early } \\
2015\end{array}$ & 89.85 & 89.86 & -0.016 & 90.88 & 90.83 & 0.057 & 89.48 & 88.69 & 0.884 \\
\hline $\begin{array}{l}\text { Early } \\
2016\end{array}$ & 84.72 & 84.69 & 0.031 & 86.44 & 86.57 & -0.150 & 83.85 & 85.70 & -2.205 \\
\hline $\begin{array}{l}\text { Early } \\
2017\end{array}$ & 79.84 & 79.86 & -0.025 & 82.40 & 82.30 & 0.117 & 81.01 & 80.04 & 1.200 \\
\hline $\begin{array}{l}\text { Early } \\
2018\end{array}$ & 75.25 & 75.25 & 0 & 78.41 & 78.43 & -0.028 & 77.16 & 77.17 & -0.010 \\
\hline $\begin{array}{l}\text { Early } \\
2019\end{array}$ & & 70.92 & & & 74.60 & & & 73.29 & \\
\hline
\end{tabular}

TABLE 13: Comparison of the predicted relative error of PCI and PQI in three forecast models of line 2.

\begin{tabular}{|c|c|c|c|c|c|c|c|c|}
\hline $\begin{array}{l}\text { Year of } \\
\text { detection }\end{array}$ & $\begin{array}{c}\text { Actual } \\
\text { measured } \\
\text { value of } \\
\text { PCI of line } \\
2 \\
\end{array}$ & $\begin{array}{l}\text { Sun Lijun } \\
\text { model's } \\
\text { prediction } \\
\text { relative error } \\
\text { (\%) }[31]\end{array}$ & $\begin{array}{l}\text { Document [31] } \\
\text { model's } \\
\text { prediction } \\
\text { relative error } \\
(\%)[31]\end{array}$ & $\begin{array}{l}\text { Prediction } \\
\text { relative error } \\
\text { of the model in } \\
\text { this paper (\%) }\end{array}$ & $\begin{array}{c}\text { Actual } \\
\text { measured } \\
\text { value of } \\
\text { PQI of line } \\
2 \\
\end{array}$ & $\begin{array}{l}\text { Sun Lijun } \\
\text { model's } \\
\text { prediction } \\
\text { relative error } \\
\quad(\%)[31]\end{array}$ & $\begin{array}{l}\text { Document [31] } \\
\text { model's } \\
\text { prediction } \\
\text { relative error } \\
(\%)[31]\end{array}$ & $\begin{array}{l}\text { Prediction } \\
\text { relative error } \\
\text { of the model in } \\
\text { this paper }(\%)\end{array}$ \\
\hline 2013 & 100 & & & & 96.96 & & & \\
\hline 2014 & 97.59 & 0.90 & 1.56 & 0 & & 0.44 & 1.07 & 0 \\
\hline 2015 & 90.89 & -1.01 & -1.23 & -0.016 & 90.88 & -0.18 & -0.24 & 0.057 \\
\hline 2016 & 86.79 & 0.25 & -0.41 & 0.031 & 86.44 & -0.29 & -0.82 & -0.150 \\
\hline 2017 & 81.41 & -0.24 & -0.59 & -0.025 & 82.40 & 0.05 & -0.32 & 0.117 \\
\hline 2018 & 77.31 & 0.33 & 0.92 & 0 & 78.41 & 0.16 & 0.63 & -0.028 \\
\hline
\end{tabular}


The GM $(1,1)$ prediction model based on the monthly attenuations of PCI and PQI not only reduces the number of matrix conditions but also improves the accuracy of prediction and lowers the relative prediction error. To put it succinctly, this model provides a new and effective way of predicting the performance of an asphalt pavement.

\section{Data Availability}

The data used to support the findings of this study are available from the corresponding author upon request.

\section{Conflicts of Interest}

The authors declare that they have no conflicts of interest.

\section{Acknowledgments}

The project was supported by the National Key Research and Development Program of China (Grant No. 2017YFC0805300), Research Foundation of Education Bureau of Hunan Province, China (Grant No. 15B010), and Open Fund of State Engineering Laboratory of Highway Maintenance Technology, Changsha University of Science \& Technology (Grant No. kfj140102).

\section{References}

[1] S. Fernandes, M. R. D. S. Hugo, and J. R. M. Oliveira, "Mechanical, surface and environmental evaluation of stone mastic asphalt mixtures with advanced asphalt binders using waste materials," Road Materials and Pavement Design, vol. 20, no. 2, pp. 316-333, 2019.

[2] F. F. Camargo and L. Bernucci, "Case history study: field monitoring and performance prediction of a field-blended rubber asphalt mixture in Brazil," International Journal of Pavement Engineering, vol. 20, no. 2, pp. 172-182, 2019.

[3] M. Kim, P. Phaltane, L. N. Mohammad, and M. Elseifi, "Temperature segregation and its impact on the quality and performance of asphalt pavements," Frontiems of Structural and Civil Engineering, vol. 12, no. 4, pp. 536-547, 2018.

[4] J. Fostinelli, E. Madeo, E. Toraldo et al., "Environmental and biological monitoring of occupational exposure to polynuclear aromatic hydrocarbons during highway pavement construction in Italy," Toxicology Letters, vol. 298, pp. 134140, 2018.

[5] D. Gardete, L. Picado-Santos, and S. Capitão, "Improving bituminous mixture performance by optimizing the design compaction energy-a cost effective approach for better pavements," Construction and Building Materials, vol. 190, pp. 1173-1181, 2018.

[6] M. Zadshir, D. J. Oldham, S. Hosseinnezhad, and E. H. Fini, "Investigating bio-rejuvenation mechanisms in asphalt binder via laboratory experiments and molecular dynamics simulation," Construction and Building Materials, vol. 190, pp. 392-402, 2018.

[7] S. Yousefdoost, E. Denneman, A. Beecroft, and B. Vuong, "Development of a national database of asphalt material performance properties in support of perpetual pavement design implementation in Australia," Construction and Building Materials, vol. 188, pp. 68-87, 2018.

[8] A. Tanakizadeh and G. Shafabakhsh, "Viscoelastic characterization of aged asphalt mastics using typical performance grading tests and rheological-micromechanical models," Construction and Building Materials, vol. 188, pp. 88-100, 2018.

[9] A. S. Braswell, R. J. Winston, and W. F. Hunt, "Hydrologic and water quality performance of permeable pavement with internal water storage over a clay soil in Durham, North Carolina," Journal of Environmental Management, vol. 224, pp. 277-287, 2018.

[10] J. Santos, S. Bressi, V. Cerezo, D. Lo Presti, and M. Dauvergne, "Life cycle assessment of low temperature asphalt mixtures for road pavement surfaces: a comparative analysis," Resources, Conservation and Recycling, vol. 138, pp. 283-297, 2018.

[11] L. Sun and X. Liu, "General deterioration equation for pavement performance," Journal of Tongji University (Natural Science), vol. 5, pp. 512-518, 1995.

[12] A. Alhasan, A. Ali, D. Offenbacker, O. Smadi, and C. LewisBeck, "Incorporating spatial variability of pavement foundation layers stiffness in reliability-based mechanistic-empirical pavement performance prediction," Transportation Geotechnics, vol. 17, pp. 1-13, 2018.

[13] K.-W. W. Lee, K. Wilson, and S. A. Hassan, "Prediction of performance and evaluation of flexible pavement rehabilitation strategies," Journal of Traffic and Transportation Engineering (English Edition), vol. 4, no. 2, pp. 178-184, 2017.

[14] A. Rezaei-Tarahomi, O. Kaya, H. Ceylan, S. Kim, K. Gopalakrishnan, and D. R. Brill, "Development of rapid three-dimensional finite-element based rigid airfield pavement foundation response and moduli prediction models," Transportation Geotechnics, vol. 13, pp. 81-91, 2017.

[15] L. Premkumar and W. R. Vavrik, "Enhancing pavement performance prediction models for the Illinois Tollway System," International Journal of Pavement Research and Technology, vol. 9, no. 1, pp. 14-19, 2016.

[16] Z. Luo, F. Xiao, S. Hu, and R. Sharma, "Bayesian updating approach for flexible pavements considering fatigue and rutting failures," Journal of Testing and Evaluation, vol. 44, no. 1, article 20140356, 2016.

[17] D. Han and S. H. Lee, "Stochastic forecasting of life expectancies considering multi-maintenance criteria and localized uncertainties in the pavement-deterioration process," Journal of Testing and Evaluation, vol. 44, no. 1, pp. 128-140, 2016.

[18] J. Deng, Grey Theory Basis, Huazhong University of Science and Technology Press, Wuhan, China, 2002.

[19] Q.-F. Hu, L. Wen, and Q.-F. Li, "Synthetical gray evaluation of asphalt pavement performance," Journal of Highway and Transportation Research and Development, vol. 23, pp. 12-15, 2006.

[20] Y.-L. Yao, L. Xue-Hong, and B.-C. Zhang, "Integrative evaluation index system for preventive maintenance timing of asphalt pavement," Journal of Traffic and Transportation Engineering, vol. 5, pp. 48-53, 2007.

[21] H. Xin, "Study on the evaluation and prediction and maintaining decision of expressway pavement performance," Master's thesis, Chang'an University, Xi'an, China, 2008.

[22] S. Wen, "Study on highway pavement maintaining management based on combining forecasting and fuzzy theory," Master's thesis, Dalian University of Technology, Dalian, China, 2009.

[23] L. Zhang, J. Ling, and Y. Zhu, "Gray and fuzzy clustering method-based on network level pavement performance assessment," Journal of Tongji University (Natural Science), vol. 38, no. 2, pp. 252-256, 2010.

[24] E. Du, S. Ma, and H. Jing, "Asphalt pavement performance prediction model based on gray system theory," Journal of 
Tongji University (Natural Science), vol. 38, no. 8, pp. 11611164, 2010.

[25] W. Yuan, "Study of asphalt pavement preventive maintenance timing on divided lanes based on the performance," Master's thesis, Chang'an University, Xi'an, China, 2011.

[26] L. Zhang, "Asphalt pavement performance prediction and analysis of selecting preventive maintenance schemes," Master's thesis, South China University of Technology, Guangzhou, China, 2012.

[27] Z. Xu, "Study on the design method of total life cycle on Hunan Province expressway asphalt pavement," Master's thesis, Changsha University of Science \& Technology, Changsha, China, 2013.

[28] Y. Li, "The timing of preventive maintenance of highway asphalt pavements," Master's thesis, Lanzhou Jiaotong University, Lanzhou, China, 2014.

[29] L. Zhou, Research of performance evaluation and prediction method of asphalt pavements for highway, Ph.D. diss, Southeast University, Nanjing, China, 2015.

[30] F. Li, "Research on the preventive maintenance decision of Chongqing expressway based on the decay law of asphalt pavement," Master's thesis, Chongqing Jiaotong University, Chongqing, China, 2016.

[31] O. Yangning, "Study on prediction of asphalt pavement performance of trunk highway in Hunan," Master's thesis, Central South University of Forestry \&Technology, Changsha, China, 2017.

[32] J. Yu, X. Zhang, and C. Xiong, "A methodology for evaluating micro-surfacing treatment on asphalt pavement based on grey system models and grey rational degree theory," Construction and Building Materials, vol. 150, pp. 214-226, 2017.

[33] Z. Wang, H. Zhang, and D. Liu, "Creating ill-conditioned matrix in GM $(1, N)$ and improve method by principal component," Journal of Jilin Teachers Institute of Engineering and Technology, vol. 21, no. 6, pp. 9-11, 2005.

[34] Y. G. Dang, Z. X. Wang, and S. F. Liu, "Research on morbidity problem of accumulating method for GM $(2,1)$ model," Systems Engineering Theory and Practices, vol. 1, pp. 156-160, 2008.

[35] J. Cui and L. S. DangYaoguo, "Study on morbidity of NGM (1, $1, \mathrm{k})$ model based on conditions of matrix," Control and Decision, vol. 25, no. 7, pp. 1050-1054, 2010.

[36] Z. Wu, L. Bo, Y. Zhang et al., "Study on the morbidity problem in grey model," Journal of Communication University of China (Science and Technology), vol. 18, no. 4, pp. 31-34, 2011.

[37] S. Liu, G. Zhang, X. Mao et al., "Research on reverse accumulating GM $(2,1)$ model and its morbidity problem," Journal of Hefei University of Technology, vol. 34, no. 4, pp. 603-608, 2011.

[38] L. Tang, "Adjust measurement unit algorithm for ill-posed problem of GM $(1,1)$ model," Geomatics and Information Science of Wuhan University, vol. 39, no. 9, pp. 1038-1042, 2014. 


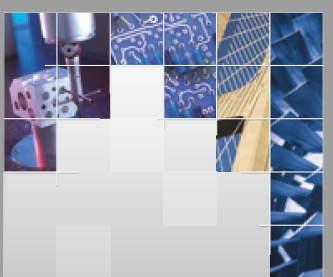

\section{Enfincering}
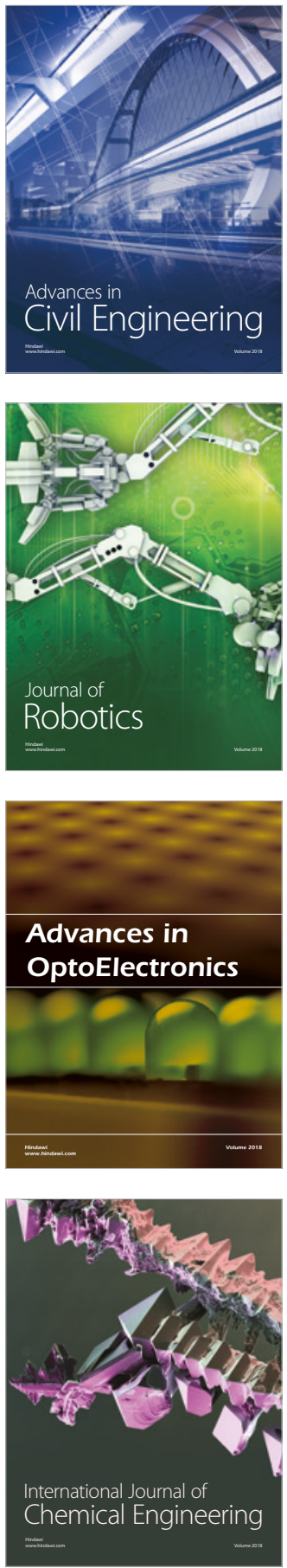

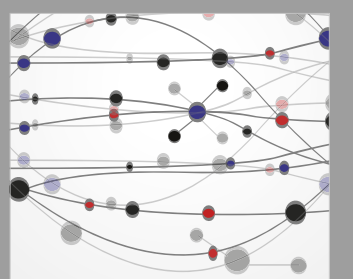

\section{Rotating \\ Machinery}

The Scientific World Journal

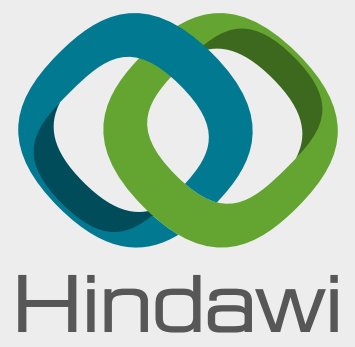

Submit your manuscripts at

www.hindawi.com
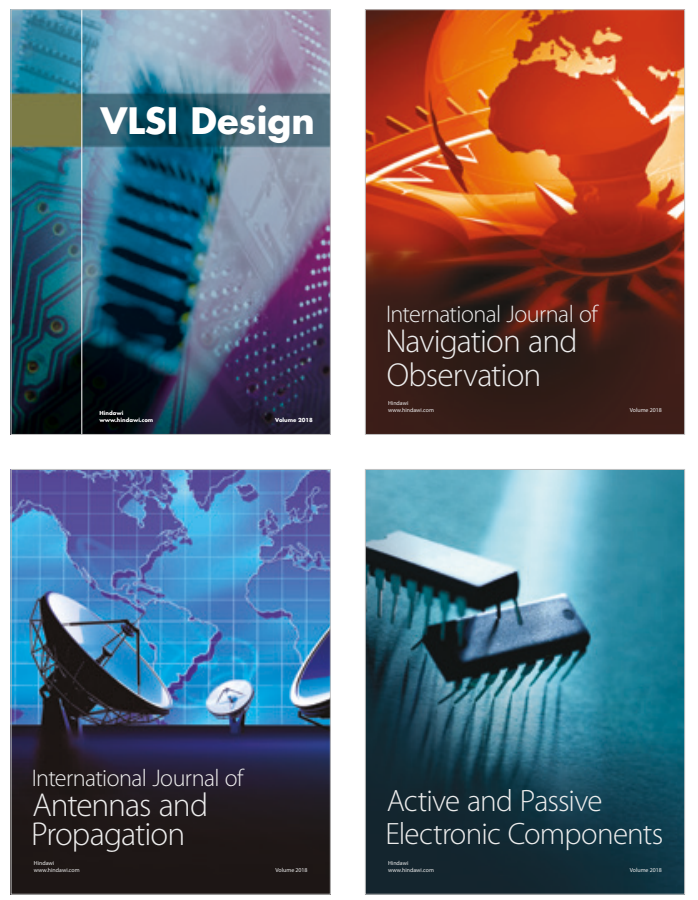
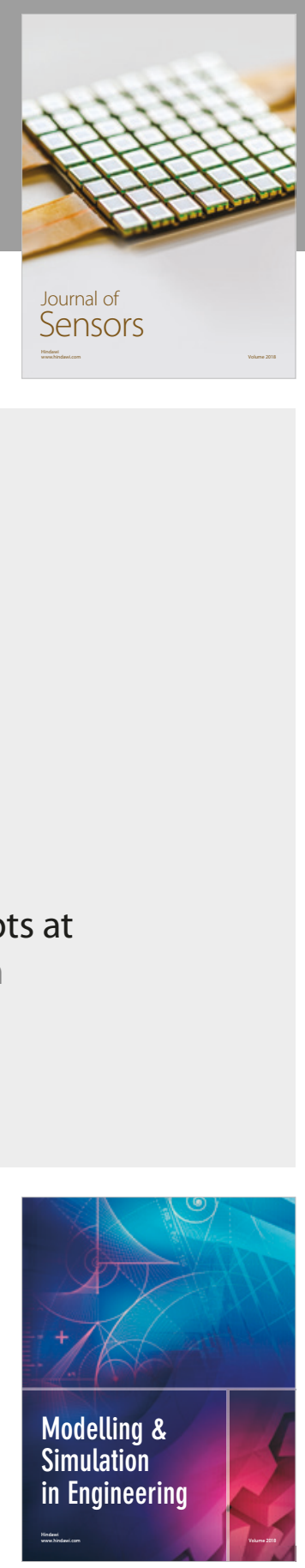

\section{Advances \\ Multimedia}
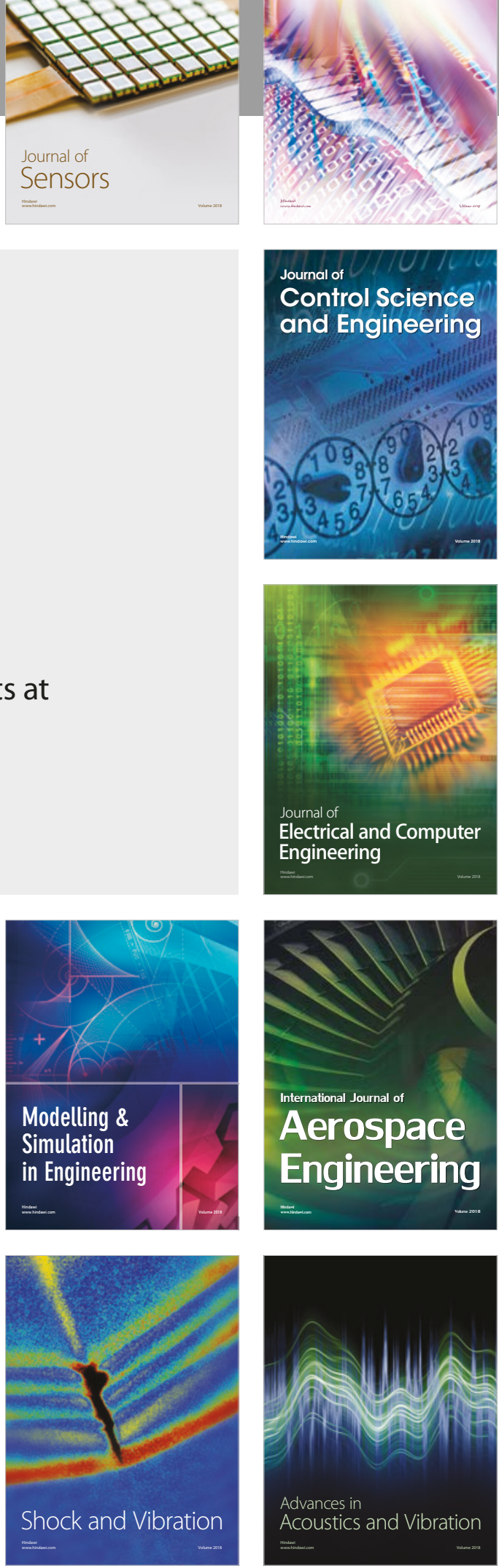